\title{
INSULIN RESISTANCE, BETA CELL FUNCTION AND LIPID PROFILE IN METABOLIC SYNDROME AND TYPE 2 DIABETES MELLITUS
}

\author{
Vijaya Lakshmi Ayyalaㅁ, Rama Krishna Malla², Ratna Kumari Gutta ${ }^{3}$ \\ ${ }^{1}$ Associate Professor, Department of Biochemistry, Kamineni Academy of Medical Sciences and Research Centre, Hyderabad. \\ ${ }^{2}$ Consultant Physician, Yashoda Hospital, Malakpet. \\ ${ }^{3}$ Professor and Ex-HOD, Department of Biochemistry, Gandhi Medical College, Hyderabad.
}

ABSTRACT

\section{BACKGROUND}

Type 2 Diabetes mellitus is the commonest form of diabetes constituting $90 \%$ of the diabetic population. The global prevalence of diabetes is estimated to increase from $4 \%$ in 1995 to $5.4 \%$ by the year 2025 . The highest prevalence of diabetes (16.6\%) is seen in the city of Hyderabad in south India, as per the survey conducted by the 'National Urban Diabetes Survey' in 2001 by Ramachandran and Sneha Latha ${ }^{7}$ et al.

The aim of our present study is to compare insulin resistance, beta cell function and the lipid profile of controls, individuals with metabolic syndrome and diabetic individuals in an urban setting like Hyderabad.

\section{MATERIALS AND METHODS}

This study is a descriptive comparative study. We enrolled 54 subjects in our study. Of the 54 subjects 15 are controls, 10 are insulin resistant/ individuals with metabolic syndrome and 29 are newly detected diabetic patients. Individuals with fasting plasma glucose $<110 \mathrm{mg} / \mathrm{dL}$ and without the minimum of three features of the metabolic syndrome set by the NCEP (Adult Treatment Panel- III) ${ }^{1}$ were selected as controls for the study. The insulin-resistant group was selected on the basis of the guideline set by the NCEP Adult Treatment Panel- III. Subjects with a minimum of three features were enrolled into the study as the insulin resistant group/ metabolic syndrome group. None of them had a fasting plasma glucose concentration of $>110 \mathrm{mg} / \mathrm{dL}$. Hence, we referred to this group as the metabolic syndrome group/ insulin resistant euglycaemic group. Fasting plasma glucose of $\geq 126$ $\mathrm{mg} / \mathrm{dL}$ on 2 occasions was taken as the primary requisite for enrolling subjects into the diabetic group as per the guidelines of ADA. Fasting blood sample of $5 \mathrm{~mL}$ was collected by venepuncture into 3 different vacutainers (NaF, EDTA and plain). Fasting plasma glucose was estimated by GOD/POD (glucose oxidase-peroxidase) method. HbA1c is assayed for glycated haemoglobin by low-pressure cation-exchange chromatography in conjunction with gradient dilution. (Courtesy- Yashoda Hospitals, Malakpet). Fasting insulin, triglycerides and HDL-C were measured in the serum. Fasting insulin was assayed by ELISA method (BioTek instruments, Yashoda Hospitals, Malakpet). Triglycerides and HDL-C was assayed by Bayer's kit on RA-50 semi auto analyzer. Reagents were purchased from Siemens and performed at Gandhi Hospital, Secunderabad.

\section{RESULTS}

Despite the small group of our present study, our findings correlated very well with the work done by previous researchers with regard to insulin resistance, pancreatic ß-cell function and lipid status in diabetes and the metabolic syndrome. HOMA-R was high in both 'metabolic syndrome' and 'type 2 diabetes mellitus' indicating insulin resistance in both the groups. Metabolic syndrome patients are able to maintain euglycaemia at the cost of hypersecretion by the pancreas. This is evident by the high HOMA-B in the metabolic syndrome group. Dyslipidaemia is a common feature found in metabolic syndrome and type 2 diabetes mellitus.

\section{CONCLUSION}

HOMA-R ${ }^{2}$ index is a simple, non-invasive useful marker for measuring 'insulin resistance.' Insulin sensitising drugs like Metformin can be used for metabolic syndrome individuals to prevent early onset of the disease and its sequel like retinopathy, nephropathy, neuropathy and cardiovascular disease. HOMA-B gives us an idea about the insulin produced by the beta cells of pancreas.

\section{KEYWORDS}

Insulin Resistance, Beta Cell Dysfunction, Lipid Profile, HOMA-R, HOMA-B.

HOW TO CITE THIS ARTICLE: Ayyala VL, Malla RK, Gutta RK. Insulin resistance, beta cell function and lipid profile in metabolic syndrome and type 2 diabetes mellitus. J. Evolution Med. Dent. Sci. 2017;6(87):6030-6033, DOI: 10.14260/jemds/2017/1311

\section{BACKGROUND}

Type 2 Diabetes mellitus is the commonest form of diabetes constituting $90 \%$ of the diabetic population. The global prevalence of diabetes is estimated to increase from $4 \%$ in

'Financial or Other Competing Interest': None.

Submission 08-10-2017, Peer Review 23-10-2017,

Acceptance 25-10-2017, Published 30-10-2017.

Corresponding Author:

Dr. Vijaya Lakshmi Ayyala

\#16-11-511/C/6, Pratap Nagar,

Moosarambagh, Hyderabad-500036.

E-mail: vijayamall09@gmail.com

DOI: $10.14260 /$ jemds/2017/1311
1995 to $5.4 \%$ by the year 2025 (King $\mathrm{H}$, Aubert RE et al, 1998). ${ }^{3}$

Epidemiological studies in India in the last decade have highlighted the increasing prevalence of type 2 diabetes in our country, especially in the urban population $(12 \%)$. This increase in the incidence of diabetes is due to increased longevity and adoption of western lifestyle. The prevalence of type 2 diabetes is high even in the rural population (7.8\%), which indicates a genetic basis for type 2 diabetes (Ramachandran, Snehalatha et al, 1999). ${ }^{4}$ Prospective and cross-sectional studies at the Diabetes Research Centre, Chennai, indicate that 'insulin resistance' is a forerunner of type 2 diabetes and cardiovascular events (Snehalatha, 
Ramachandran et al, 1998). 5 The highest prevalence of diabetes $(16.6 \%)$ is seen in the city of Hyderabad in south India, as per the survey conducted by the 'National Urban Diabetes Survey' in 2001. Keeping in view the increasing prevalence of type 2 diabetes and insulin resistance in the urban Indian population, the present study was taken up in Hyderabad.

The aim of the present study is to compare insulin resistance, beta cell function and the lipid profile of controls, individuals with metabolic syndrome and diabetic individuals in an urban setting like Hyderabad.

\section{MATERIALS AND METHODS}

This study is a descriptive comparative study. We enrolled 54 subjects in our study. Of the 54 subjects 15 were controls, 10 were insulin resistant and 29 were newly detected diabetic patients. Sample size was taken conveniently.

\section{The Inclusion Criteria for each of these groups is given} below-

a. Individuals with fasting plasma glucose $<110 \mathrm{mg} / \mathrm{dL}$ and without the minimum of three features of the metabolic syndrome set by the Inclusion criteria were enrolled as the control group.

b. Newly diagnosed type II diabetics, Fasting Plasma Glucose $\geq 126 \mathrm{mg} / \mathrm{dL}$ on at least 2 occasions as per the ADA guidelines.

c. Metabolic syndrome group or the insulin resistant group will be selected on the basis of the guidelines set up by the NCEP Adult Treatment panel- III. ${ }^{1}$

\begin{tabular}{|c|c|}
\hline Risk Factor & Defining Value \\
\hline 1. Abdominal Obesity & $>40$ inches \\
\hline Men & $>35$ inches \\
\hline Women & $\geq 150 \mathrm{mg} / \mathrm{dL}$ \\
\hline 2. Triglycerides & \\
\hline 3. HDL-C & $<40 \mathrm{mg} / \mathrm{dL}$ \\
\hline Men & $<50 \mathrm{mg} / \mathrm{dL}$ \\
\hline Women & $\geq 130 / 85 \mathrm{mmHg}$ \\
\hline 4. Blood Pressure & $\geq 110 \mathrm{mg} / \mathrm{dL}$ \\
\hline 5. Fasting Plasma Glucose &
\end{tabular}

*Three or more features are required to make the diagnosis of Metabolic syndrome.

\section{Exclusion Criteria}

Longstanding diabetics, newly diagnosed type II diabetics who were on medication, chronic hypertensives, congenital hyperlipoproteinaemia heart failure and renal failure patients were excluded from the study.

Fasting blood sample of $5 \mathrm{~mL}$ was collected by venepuncture into 3 different vacutainers (NaF, EDTA and plain). Fasting plasma glucose was estimated by GOD/POD (glucose oxidase-peroxidase) method. HbA1c is assayed for glycated haemoglobin by low-pressure cation-exchange chromatography in conjunction with gradient dilution. (Courtesy- Yashoda Hospitals, Malakpet).

Fasting insulin, triglycerides and HDL-C were measured in the serum. Fasting insulin was assayed by ELISA method (BioTek instruments, Yashoda Hospitals, Malakpet). Triglycerides and HDL-C was assayed by Bayer's kit on RA-50 semi auto analyzer. Reagents were purchased from Siemens and performed at Gandhi Hospital, Secunderabad.
Statistical analysis was performed using the SPSS 17 version. Test used is One Way ANOVA with post-hoc test.

\section{RESULTS}

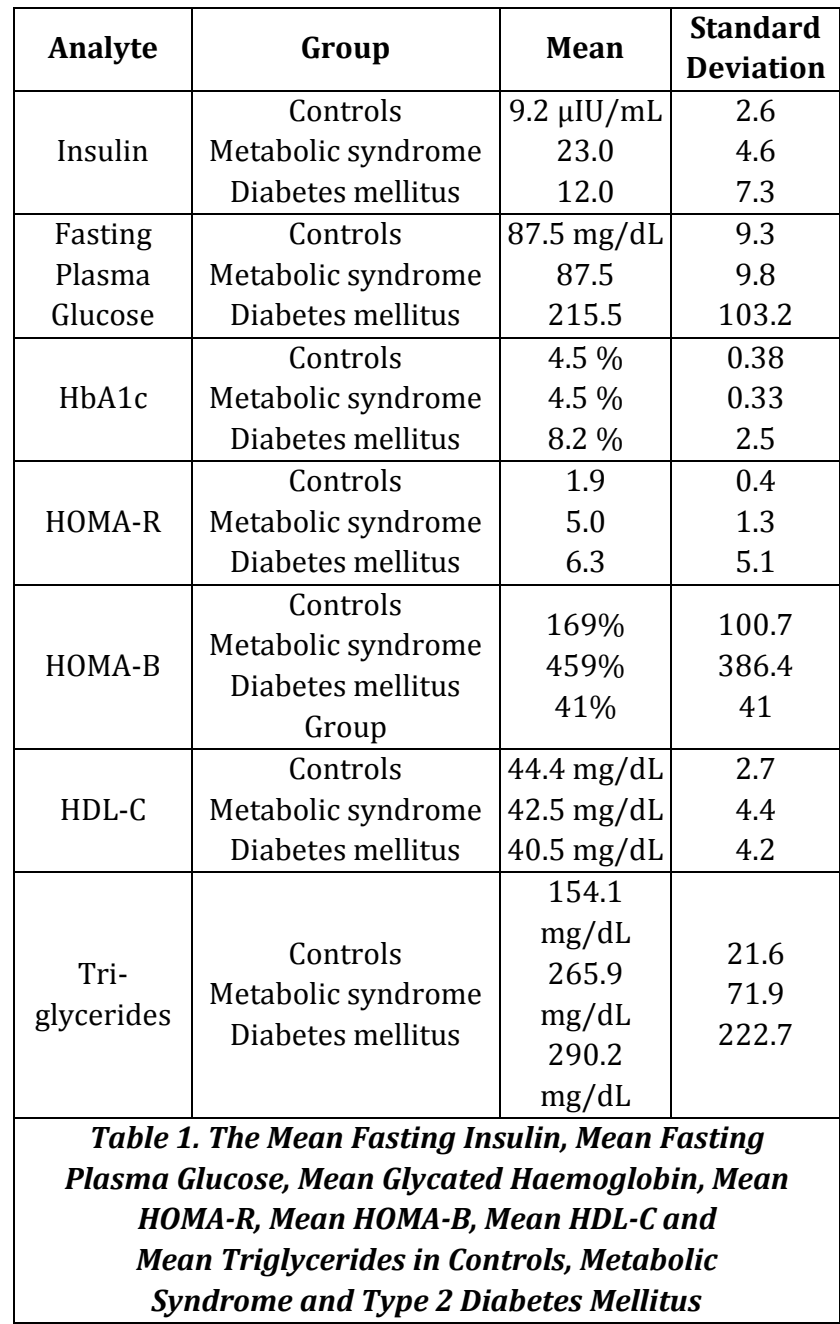

\begin{tabular}{|c|c|c|}
\hline Analyte & Groups & P value \\
\hline $\begin{array}{l}\text { Fasting } \\
\text { Insulin }\end{array}$ & $\begin{array}{l}\text { Controls vs Metabolic syndrome } \\
\text { Controls vs diabetes } \\
\text { Diabetes vs metabolic syndrome }\end{array}$ & $\begin{aligned}< & 0.001 \\
& 0.15 \\
< & 0.001\end{aligned}$ \\
\hline $\begin{array}{l}\text { Fasting } \\
\text { Plasma } \\
\text { Glucose }\end{array}$ & $\begin{array}{l}\text { Controls vs Metabolic syndrome } \\
\text { Controls vs diabetes } \\
\text { Diabetes vs metabolic syndrome }\end{array}$ & $\begin{array}{r}0.997 \\
<0.001 \\
<0.001\end{array}$ \\
\hline $\mathrm{HbA1c}$ & $\begin{array}{l}\text { Controls vs Metabolic syndrome } \\
\text { Controls vs diabetes } \\
\text { Diabetes vs metabolic syndrome }\end{array}$ & $\begin{aligned} & 0.7 \\
< & 0.001 \\
< & 0.001\end{aligned}$ \\
\hline HOMA-R & $\begin{array}{l}\text { Controls vs Metabolic syndrome } \\
\text { Controls vs diabetes } \\
\text { Diabetes vs metabolic syndrome }\end{array}$ & $\begin{array}{c}0.05 \\
0.001 \\
0.41\end{array}$ \\
\hline HOMA-B & $\begin{array}{l}\text { Controls vs Metabolic syndrome } \\
\text { Controls vs diabetes } \\
\text { Diabetes vs metabolic syndrome }\end{array}$ & $\begin{array}{c}<0.001 \\
0.003 \\
<0.001\end{array}$ \\
\hline HDL-C & $\begin{array}{l}\text { Controls vs Metabolic syndrome } \\
\text { Controls vs diabetes } \\
\text { Diabetes vs metabolic syndrome }\end{array}$ & $\begin{array}{c}0.1 \\
0.003 \\
0.2\end{array}$ \\
\hline Triglycerides & $\begin{array}{l}\text { Controls vs Metabolic syndrome } \\
\text { Controls vs diabetes } \\
\text { Diabetes vs metabolic syndrome }\end{array}$ & $\begin{array}{c}<0.001 \\
0.01 \\
0.4\end{array}$ \\
\hline \multicolumn{3}{|c|}{ Table 2. Multiple Comparison of Variants } \\
\hline
\end{tabular}




\section{DISCUSSION}

In our study, the mean fasting insulin is $9.2 \mu \mathrm{IU} / \mathrm{mL}$ in controls, $23.0 \mu \mathrm{IU} / \mathrm{mL}$ in the metabolic syndrome group and $12.0 \mu \mathrm{IU} / \mathrm{mL}$ in the diabetic group. The markedly elevated fasting insulin in the insulin resistant group in our study confirms the previous studies by Godsland IF and Stern MO $^{6}$ et al that insulin concentration is directly related to the severity of insulin resistance and can be used as a surrogate marker for tissue insulin resistance.

The mean fasting plasma glucose is $87.5 \mathrm{mg} / \mathrm{dL}$ in controls, $87.6 \mathrm{mg} / \mathrm{dL}$ in the metabolic syndrome group and $215.5 \mathrm{mg} / \mathrm{dL}$ in the diabetic group. From these statistics, it is evident that there is not much variation in the fasting plasma glucose concentration in the control and metabolic syndrome groups. Insulin resistant individuals maintain euglycaemic status at the expense of pancreatic oversecretion as indicated by the high insulin values. A state of decompensation indicated by an insignificant elevation in insulin concentration in the diabetic group leads to elevated fasting plasma glucose concentrations of $215.5 \mathrm{mg} / \mathrm{dL}$ in the diabetic group.

The mean glycated haemoglobin is $4.5 \%$ in controls, $4.6 \%$ in the insulin-resistant group and $8.2 \%$ in the diabetic group. The mean glycated haemoglobin values confirm the glycaemic status of the 3 subgroups.

In our study, the mean insulin resistance index (HOMA-R) is 1.97 in controls, 5.01 in the metabolic syndrome group and 6.3 in the diabetic group. The above data clearly shows that the control group has the lowest HOMA-R of the three groups and insulin resistance is a common feature to the metabolic syndrome (insulin resistant, euglycaemic) group and the diabetic group. But HOMA-R index is the highest in the diabetic group. This can be explained by the formula we use to calculate the HOMA-R index, (Mathews² 1985).

HOMA- R: Fasting Insulin $\times$ Fasting Plasma glucose $\mathrm{mmol} / \mathrm{L}$

One noteworthy point from the above formula is 'fasting plasma glucose concentration is a reflection of the sensitivity of the hepatic tissue to insulin action.' Greater the insulin sensitivity greater is the inhibition on gluconeogenesis in the fasting state by the lone hypoglycaemic hormone, insulin and a resultant decrease in the fasting plasma glucose. In Metabolic syndrome and Diabetes, there is a variable degree of insulin resistance and a reversal of these pathophysiological mechanisms resulting in elevated fasting plasma glucose. Determining the cut-off point for HOMA-R was based on an article entitled 'Identification of individuals with insulin resistance using routine clinical measurements' by Steven E Stern in the Journal of Diabetes. The article clearly stated that HOMA-R $\geq 3.6$ must be considered as insulin resistant. The lowest HOMA-R in our study was 3.8, which reiterates the findings by Steven E Stern.7

The mean HOMA-B is $169.3 \%$ in controls, $459 \%$ in insulin resistant and $46 \%$ in diabetes. The pancreatic beta cells secrete adequate amount of insulin in the basal state as indicated by a mean value of $169 \%$ in controls, which maintains an euglycaemic status. In the metabolic syndrome group, a compensatory hyperinsulinaemia ${ }^{8}$ in the presence of insulin resistance achieves normal or near normal euglycaemic levels. In the diabetic group, a decompensation in the pancreatic beta cell function indicated by the lowest mean HOMA-B of $41 \%$, in the presence of variable degrees of insulin resistance leads to hyperglycaemia. These findings in our study reiterate the role of pancreatic hyposecretion and insulin resistance in the development of Diabetes Mellitus.

\begin{tabular}{|c|c|}
\hline HOMA-B: & $20 \times$ Fasting Insulin \\
\hline
\end{tabular}

Lipid abnormalities are common in type 2 diabetes mellitus and hence HDL-C and triglycerides were measured in all the sub-groups and subjected to statistical analysis. The mean HDL-C concentration is $44.4 \mathrm{mg} / \mathrm{dL}$ in controls, 42.5 $\mathrm{mg} / \mathrm{dL}$ in metabolic syndrome group and $40.5 \mathrm{mg} / \mathrm{dL}$ in the diabetic group. On sub-group comparison, the ' $p$ ' value is 0.1 between the control and the metabolic syndrome group. This can probably be explained by the presence of 7 young females in a group of 10 in the metabolic syndrome group. Oestrogen which is abundant in women inhibits the activity of hepatic lipase- an enzyme that catalyses the degradation of HDL-C and hence a higher HDL-C in women in the reproductive age group. The $\mathrm{p}$ value is 0.2 between the metabolic syndrome group and the diabetic group, which is insignificant, which indicates HDL is comparable in both the groups.

The mean triglyceride concentration is $154.13 \mathrm{mg} / \mathrm{dL}$ in controls, $265 \mathrm{mg} / \mathrm{dL}$ in insulin resistance and $290 \mathrm{mg} / \mathrm{dL}$ in diabetics. The $\mathrm{p}$ value with respect to triglycerides between controls and the metabolic syndrome is $<0.01$. The $p$ value between the metabolic syndrome group and the diabetic group is $>0.1$, which means to say that hypertriglyceridaemia is a common feature to both the conditions. The $\mathrm{p}$ value is < 0.01 between controls and diabetics. This is significant. From these data, it is evident that diabetes and insulin resistance are associated with variable dyslipidaemia. This characteristic picture termed diabetic dyslipidaemia characterised by high triglyceride and a low HDL-C concentration has been attributed to inactivation of 'lipoprotein lipase' and activation of hormone sensitive lipase. In insulin resistance, 'lipoprotein lipase' is inactivated resulting in impaired hydrolysis of triglyceride rich lipoproteins and increased degradation.

One noteworthy point in our study is that both metabolic syndrome and type 2 diabetes mellitus are characterised by variable degrees of dyslipidaemia with respect to the control group. But it is too premature to comment on whether insulin resistance precedes dyslipidaemia or dyslipidaemia precedes insulin resistance, as our study is not a prospective study. Two prospective studies by Haffner and Mykkanen ${ }^{9}$ demonstrated that hyperinsulinaemia precedes dyslipidaemia. But, Yki-Jarvinen ${ }^{10}$ (1988) proposed that subjects with endogenous hypertriglyceridaemia are resistant to the glucoregulatory effects of insulin, i.e. 'dyslipidaemia precedes insulin resistance.'

\section{CONCLUSION}

Insulin resistance is a forerunner of Diabetes. And, hence measuring insulin resistance can help us in assessing the tendency to develop Diabetes Mellitus. HOMA-R index is a simple, non-invasive, useful marker for measuring 'insulin resistance.' Insulin sensitising drugs like Metformin can be used for metabolic syndrome individuals to prevent early onset of the disease and its sequelae like retinopathy, 
nephropathy, neuropathy and cardiovascular disease. HOMA$\mathrm{B}$ gives us an idea about the insulin produced by the beta cells of pancreas

Our study is a descriptive comparative study. Prospective studies must be carried out to know whether dyslipidaemia causes insulin resistance or insulin resistance causes dyslipidaemia.

\section{REFERENCES}

[1] Expert Panel on detection, Evaluation and treatment of high blood cholesterol in adults. Executive summary of the third report of the National Cholesterol Education Programme (NCEP) Expert panel on Detection, Evaluation and treatment of high blood cholesterol in adults (Adult Treatment Panel III). JAMA 2001;285(19):2486-97.

[2] Matthews DR, Hosker JP, Rudenski AS, et al. Homeostasis model assessment: insulin resistance and beta-cell function from fasting plasma glucose and insulin concentrations in man. Diabetologia 1985;28(7):412-9.

[3] King H, Aubert RE, Herman WH. Global burden of diabetes, 1995-2025: prevalence, numerical estimates and projections. Diabetes Care 1998;21(9):1414-31.
[4] Ramchandran A, Snehalatha C, Latha E, et al. Impacts of urbanization on the lifestyle and on the prevalence of diabetes in native Asian Indian population. Diab Res Clin Pract 1999;44(3):207-13.

[5] Snehalatha C, Ramachandran A, Satyavani K, et al. Study of genetic pre diabetic south Indian subjects. Importance of hyperinsulinemia and beta-cell dysfunction. Diabetes Care 1998;21(1):76-9.

[6] Godsland IF, Stevenson JC. Insulin resistance: syndrome or tendency? Lancet 1995;346(8967):1003.

[7] Stern SE, Williams K, Ferrannini E, et al. Identification of individuals with insulin resistance using routine clinical measurements. Diabetes 2005;54(2):333-9.

[8] Haffner SM, Valdez RA, Hazuda HP, et al. Prospective analysis of the insulin-resistance syndrome (syndrome X). Diabetes 1992;41(6):715-22.

[9] Mykkanen L, Kuusisto J, Haffner SM, et al. Hyperinsulinemia predicts multiple atherogenic changes in lipoproteins in elderly subjects. Arterioscler Thromb 1994;14(4):518-26.

[10] Yki-Jarvinen H, Taskinen MR, Koivisto VA, et al. Response of adipose tissue lipoprotein lipase activity and serum lipoproteins to acute hyperinsulinemia in man. Diabetologia 1984;27:364-9. 